\title{
STUDY OF GASTROINTESTINAL PARASITES OF DEER AT CHAR KUKRI MUKRI IN BHOLA DISTRICT
}

\author{
B. C. Barmon, N. Begum, S. S. Labony*, U. K. Kundu, A. R. Dey and T. R. Dey \\ Department of Parasitology, Faculty of Veterinary science, Bangladesh Agricultural University, Mymensingh- \\ 2202, Bangladesh
}

\begin{abstract}
To study the prevalence of gastrointestinal parasites of deer, 127 fecal samples were collected from Char Kukri Mukri upazilla of Bhola district of Bangladesh during the period from January to May, 2013. Eighty eight samples were found to be infected with gastrointestinal parasites and overall prevalence rate was $69.29 \%$. Fasciola sp. (8.66\%), Paramphistomum sp. $(20.47 \%)$, stomach worm (18.11\%), hook worm (20.47\%), Strongyloides sp. (1.57\%), Oesophagostomum sp. (1.57\%), Eimeria sp. (6.30\%) and Balantidium coli $(1.57 \%)$ were found. The overall prevalence of nematode, trematode, protozoan and mixed infection were $29.13 \%, 25.19 \%, 5.51 \%$ and $9.45 \%$ respectively. Seasonal prevalence of gastrointestinal parasites in summer and winter were $70.59 \%$ and $66.67 \%$ respectively. The range of EPG/CPG/OPG varied from 100 to 300 among the parasites and highest count was found in Paramphistomum sp. (300), hook worm (300) and stomach worm (300). This study provided a first overview on parasites in deer in the vicinity of villages, but to evaluate parasite transmission dynamics much more studies were required on livestock and on wild herbivores.
\end{abstract}

Key Words: Deer, Gastrointestinal parasites, Prevalence

\section{INTRODUCTION}

Deer is the ruminant wildlife having economic value worldwide. In Bangladesh, deer are mostly available in Sundarban, Chittagong Hill tracts and different areas of Bhola and Noakhali district. Disease monitoring in wild animals has recently become a necessary component for preventing nature and human being. The presence of parasites in an animal, particularly in young animals resulting lowered condition, reduced body weight gains and reproductive disorders; in addition, the parasites affect the quality of animal products (meat, skin, antlers) and ultimately death (Fox, 2000). Infections with helminthes are a major health issue in captive and wild deer (Goossens et al., 2005) mainly where herds of animals are kept in relatively small enclosures. These wild animals live in nature in large areas and have consequently a low genetic resistance against parasitic infections. A few studies have addressed on captive areas in Bangladesh have shown that helminthes harbored by different species of deer are not so distinct from those of feral and domestic livestock (Islam et al., 2003). Although a number of researches have been performed on the parasitism in livestock and poultry in Bangladesh, but rarely any attempt was made to conduct study exploring the prevalence and the effects of parasitism in the deer. Deer are hosts to a wide range of endoparasites such as helminths, insect larvae and certain protozoa (Rehbein et al., 2001; Vengust, 2003) cestodes (Chapman and Chapman, 1997) and other ectoparasites. Outbreaks of parasitic diseases among farmed deer in a limited space and intensive management practices mean that they are more heavily infested with parasites than wild deer (Vengust, 2003). Application of existing knowledge of disease control and prevention would significantly reduce economic losses due to gastrointestinal helminthiasis. In addition, investment to improve technology for disease diagnosis, control, prevention and/or eradication, along with adoption of that technology should yield significant dividends for deer industry (Mackintosh and Wilson, 2003). Although outbreaks of parasitic diseases in deer are not so deadly but it is out most important to keep the deer free from parasite. In captive deer, parasites such as gastrointestinal nematodes, Dictyocaulus viviparous and Elaphostrongylus cervi are common (Fletcher, 1982; Mason and Gladen, 1983; Mason, 1994) and often cause mortality and morbidity in deer (Fletcher, 1982). Some research has done by the scientist to determine the prevalence of captive deer but no detail work have done in deer at wild condition. Therefore, this present study attempts to identify the gastrointestinal parasites and to determine the prevalence and intensity of parasitic infection in deer at wild condition.

*Corresponding e-mail address: labonydvm4@gmail.com 


\section{B. C. Barmon and others}

\section{MATERIALS AND METHODS \\ Study area}

The study was conducted in different areas of Bhola district such as Char Kukri Mukri, Charpatila and Dhal char. Fecal samples were examined in the laboratory, Department of Parasitology, Bangladesh Agricultural University (BAU), Mymensingh.

\section{Selection of animals}

The study covered the all ages and sexes of deer found in Char Kukri Mukri. One hundred and twenty seven (127) deers were selected randomly.

\section{Collection of fecal samples}

Fecal samples were collected from the ground after defecation at morning of the day. Proper care was taken when fecal sample was collected from the ground to prevent contamination. After collection of fecal sample, about 20-25 grams of feces were placed in a polythene bag. Each sample was kept in separate polythene bag with $10 \%$ formalin to identify the eggs of parasite then tied carefully and numbered properly. The correctly labeled and properly numbered polythene bags containing the fecal samples with all required information were brought to the laboratory and refrigerated at $4^{\circ} \mathrm{C}$ and examined.

\section{Examination of fecal samples}

All samples were examined in the laboratory of the Department of Parasitology, BAU, Mymensingh. The samples were processed for microscopic examination. The ova/cysts/oocyst/larvae of different parasites were identified according to the morphology and quantitative estimation was done by applying Modified Stoll's ova dilution technique to determine eggs per gram (EPG) or cyst per gram (CPG) or oocyst per gram (OPG) of feces as described by Soulsby (1982).

\section{Statistical analysis}

Data were analyzed by using Statistical Package for Social Science (SPSS). 'F' Test were performed and the result were expressed in percentage with $\mathrm{P}$-value and significance was determined when $\mathrm{P}<0.05$.

\section{RESULTS AND DISCUSSION}

\section{Overall prevalence of gastrointestinal parasites in deer at Char Kukri Mukri}

During this study, a total of 127 fecal sample in deer were examined, of which $88(69.29 \%)$ were found to be infected with one or more species of gastrointestinal parasites. These findings support the earlier reports of (Pilarczyk et al., 2005; Pacon, 1994; Cisek et al., 2004 and Santin et al., 2004). A total of eight species of gastrointestinal parasites (ova/cyst/oocyst) were identified, namely, Fasciola sp. (8.66\%), Paramphistomum sp. (20.47\%), stomach worm (18.11\%), hook worm (20.47\%), Strongyloides sp. (1.57\%), Oesophagostomum sp. (1.57\%), Eimeria sp. (6.30\%) and Balantidium coli (1.57\%). Paramphistomum sp. and Haemonchus sp. were common but earlier report (Kanungo et al., 2010) showed Fasciola sp. was found only in Dhaka zoo and Safari Park.

The Fasciola sp. was recorded $8.66 \%$ which was less than reported by (Kanungo et al., 2010). They reported strong infection of Fasciola sp. were $20 \%$ and $12.5 \%$ in spotted deer and sambar deer in Dhaka zoo and $19.05 \%, 25 \%$ and $36.36 \%$ in spotted deer, sambar deer and para deer respectively in Safari park. It was evident from these results that deer was susceptible to Fasciola sp. The infection with Fasciola sp. was found similar to the findings of (Vengust, 2003; Novobilsky et al., 2007; Chroust and Chroustova, 2004; Maia, 2001). The probable cause of higher infection rate Fasciola sp. was strongly connected with mud snails that live on the edges of drain and act as intermediate host (Vengust, 2003).

Paramphistomum sp. and hook worm were highly prevalent in deer and the rates of prevalence were $20.47 \%$. Strongyloides sp., Oesophagostomum sp. and B. coli were found less in prevalent. It appeared from the results that stomach worm (18.11\%) was found most frequently in feces. More or less similar prevalence rates of stomach worm have been reported earlier by (Cook et al., 1979; Mckenzie and Davidson, 1989; Mason, 1994). Paramphistomum sp. (20.47\%) was highly prevalent as observed in this study was supported by the previous reports of (Islam et al., 2003; Banerjee et al., 2005). 
The study recorded an overall prevalence of both Strongyloides sp. Oesophagostromum sp. were 1.57\% each, hook worm was $20.47 \%$. More or less similar prevalence rate of gastrointestinal nematodiasis have been reported earlier by Shibashi et al. (2003), Santin et al. (2004), Maia (2001), Islam et al. (2003), Cook et al. (1979). However, some variation on the prevalence rate of helminthes were exist which might be due to topographic variation of the study area, environment, season and duration of study which influence the prevalence of the infection.

The overall prevalence of parasitic infection was $69.29 \%(88 / 127)$, where nematode, trematode and protozoan were $29.13 \%$ (37/127), 25.19\% (32/127) and 5.51\% (7/127), respectively (Table 1). Results indicated that helminth infections were more common than protozoan infection in deer. In this study the prevalence of helminth infection $(54.32 \%)$ was found higher than protozoan infection $(5.51 \%)$. This was more or less similar with the report of Parasani et al. (2001) who revealed that 50\% animals positive for helminth infections and $18.8 \%$ with protozoa in Rajkot Municipal Corporation zoo. Lim et al. (2008) reported 34.5\% positive with helminthes and $21.8 \%$ positive with protozoa which are much lower than the present study in case of helminth infections but higher in case of protozoan infection. This may be happened due to local climatic conditions, method of sample collection and use of anthelmintic in captive animal helminths $(82.2 \%)$ than protozoa $(17.8 \%)$.

In this study, EPG/CPG/OPG (eggs/cysts/oocysts per gram of feces) was also determined. The range of EPG/CPG/OPG varied among the parasites and ranged from 100 to 300. The highest EPG/CPG/OPG was counted in case of Paramphistomum sp. (300), hook worm (300) and stomach worm (300) followed by Balantidium coli (200), Eimeria sp. (200), Fasciola sp., Oesophagostomum sp. and Strongyloides sp. had the

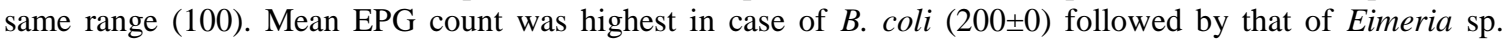

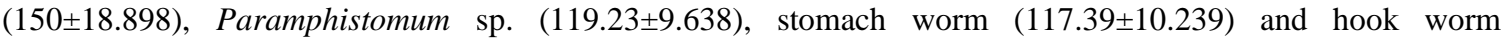

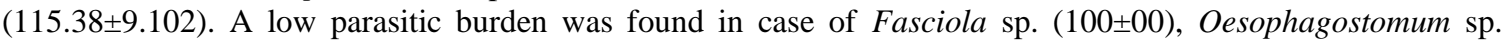
$(100 \pm 00)$ and Strongyloides sp. $(100 \pm 00)$.

Table 1. Overall prevalence of gastrointestinal parasites in deer at Char Kukri Mukri

\begin{tabular}{|lllll|}
\hline Name of Parasites & $\begin{array}{l}\text { No. Infected } \\
(\text { Total No=127) }\end{array}$ & Prevalence (\%) & EPG & \\
\cline { 4 - 5 } & & & Range & Mean \pm SE \\
\hline Fasciola sp. & 11 & 8.66 & 100 & $100 \pm 00$ \\
Paramphistomum sp. & 26 & 20.47 & $100-300$ & $119.23 \pm 9.638$ \\
Hook worm & 26 & 20.47 & $100-300$ & $115.38 \pm 9.102$ \\
Oesophagostomum sp. & 2 & 1.57 & 100 & $100 \pm 00$ \\
Stomach worm & 23 & 18.11 & $100-300$ & $117.39 \pm 10.239$ \\
Strongyloides sp. & 2 & 1.57 & 100 & $100 \pm 00$ \\
Eimeria sp. & 8 & 6.3 & $100-200$ & $150 \pm 18.898$ \\
Balantidium coli & 2 & 1.57 & 200 & $200 \pm 00$ \\
\hline Sub total & $\mathbf{8 8}$ & $\mathbf{6 9 . 2 9}$ & $\mathbf{1 0 0 - 3 0 0}$ & $\mathbf{1 3 6 . 0 5} \pm \mathbf{6 . 8 0 2}$ \\
\hline
\end{tabular}

\section{Prevalence of mixed infection in deer at Char Kukri Mukri}

Overall prevalence of mixed infection was $9.45 \%$ (12/127). Type of mixed infection detected in this study were Oesophagostomum sp. and hook worm (1), stomach worm and hook worm (3), Paramphistomum sp. and hook worm (1), Paramphistomum sp. and stomach worm (3), Fasciola sp. and stomach worm(1), Eimeria sp. and hook worm(2), Eimeria sp. and stomach worm (2). Their prevalence rate were $0.78 \%, 2.36 \%, 0.78 \%, 2.36 \%$, $0.78 \%, 1.57 \%$ and $0.78 \%$, respectively (Table 2 ). In this study, mixed infection was observed in twelve deer. The mixed infection in zoo animal was recorded by Kanungo et al. (2010) and in monkeys by Mutani et al. (2003) who commented that $58.5 \%$ of all monkeys examined had at least three parasite species and only $34.0 \%$ had between one and two parasite species. 


\section{B. C. Barmon and others}

Table 2. Prevalence of mixed infection in deer at Char Kukri Mukri

\begin{tabular}{|lll|}
\hline Name of parasite & No. of case & Prevalence (\%) \\
\hline Oesophagostomum sp. and hook worm & 01 & 0.78 \\
Hook worm and stomach worm & 03 & 2.36 \\
Paramphistomum sp. and hook worm & 01 & 0.78 \\
Paramphistomum sp. and stomach worm & 03 & 2.36 \\
Fasciola sp. and stomach worm & 01 & 0.78 \\
Eimeria sp. and hook worm & 02 & 1.57 \\
Eimeria sp. and stomach worm & 01 & 0.78 \\
\hline Sub total & $\mathbf{1 2}$ & $\mathbf{9 . 5}$ \\
\hline
\end{tabular}

Seasonal prevalence of gastrointestinal parasites in deer at Char Kukri Mukri

Seasonal fluctuation of the year had a significant $(\mathrm{p}<0.05)$ effect on the prevalence of gastrointestinal parasitic infection in deer. A relatively higher infection with gastrointestinal parasites were observed in summer $(70.59 \%)$ than in winter (66.67\%) (Table 3). The present finding is much higher than the previous reports of Azhar et al. (2002) who reported the highest prevalence in autumn (24.0\%) followed by spring (20.0\%), winter (13.0\%), while the lowest $(9.0 \%)$ was recorded during summer in Pakistan. The contrast in between the present and earlier findings can be explained by the fact of variation in the geographical location of the study area and also the methods used in the study.

Table 3. Seasonal prevalence of gastrointestinal parasites in deer at Char Kukri Mukri

\begin{tabular}{|c|c|c|c|c|c|c|c|c|}
\hline \multirow[t]{3}{*}{ Name of parasite } & \multicolumn{4}{|c|}{ Summer $(N=67)$} & \multicolumn{4}{|c|}{ Winter $(\mathrm{N}=60)$} \\
\hline & \multirow{2}{*}{$\begin{array}{l}\text { No. } \\
\text { infected }\end{array}$} & \multirow{2}{*}{$\begin{array}{l}\text { Prevale } \\
\text { nce }(\%)\end{array}$} & \multicolumn{2}{|r|}{ EPG } & \multirow{2}{*}{$\begin{array}{l}\text { No. of } \\
\text { infected }\end{array}$} & \multirow{2}{*}{$\begin{array}{l}\text { Preval } \\
\text { ence } \\
(\%)\end{array}$} & \multicolumn{2}{|r|}{ EPG } \\
\hline & & & Range & Mean \pm SE & & & Range & Mean \pm SE \\
\hline Fasciola sp. & 5 & 7.35 & 100 & $100 \pm 00$ & 6 & 10 & 100 & $100 \pm 00$ \\
\hline $\begin{array}{l}\text { Paramphistomum } \\
\text { sp. }\end{array}$ & 15 & 22.06 & $\begin{array}{l}100- \\
300\end{array}$ & $133.33 \pm 15.936$ & 11 & 18.33 & 100 & $100 \pm 00$ \\
\hline Strongyloides sp. & 1 & 1.47 & 100 & $100 \pm 00$ & 1 & 1.67 & 100 & $100 \pm 00$ \\
\hline $\begin{array}{l}\text { Oesophagostomum } \\
\text { sp. }\end{array}$ & 2 & 2.94 & 100 & $100 \pm 00$ & - & - & - & - \\
\hline Stomach worm & 12 & 17.65 & $\begin{array}{l}100- \\
300\end{array}$ & $125 \pm 17.944$ & 11 & 18.33 & $100-200$ & $109.09 \pm 9.091$ \\
\hline Hook worm & 14 & 20.59 & $\begin{array}{l}100- \\
300\end{array}$ & $128.57 \pm 16.336$ & 12 & 20 & 100 & $100 \pm 00$ \\
\hline B. coli & 1 & 1.47 & 200 & $200 \pm 00$ & 1 & 1.67 & 200 & $200 \pm 00$ \\
\hline Eimeria sp. & 5 & 7.35 & $\begin{array}{l}100- \\
200\end{array}$ & $180 \pm 20.00$ & 3 & 5 & $100-200$ & $166.67 \pm 33.33$ \\
\hline Sub total & 48 & 70.59 & $\begin{array}{l}100- \\
300\end{array}$ & $150 \pm 10.314$ & 40 & 66.67 & $100-300$ & $122.5 \pm 7.585$ \\
\hline
\end{tabular}




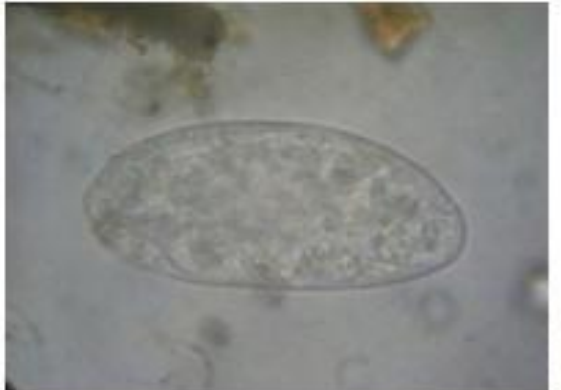

Plate 1. Egg of Paramphistomum sp. (720X)

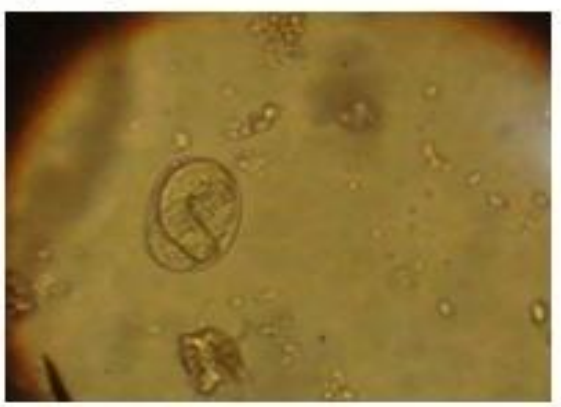

Plate 3. Egg of Strongyloides sp. $(720 \mathrm{X})$

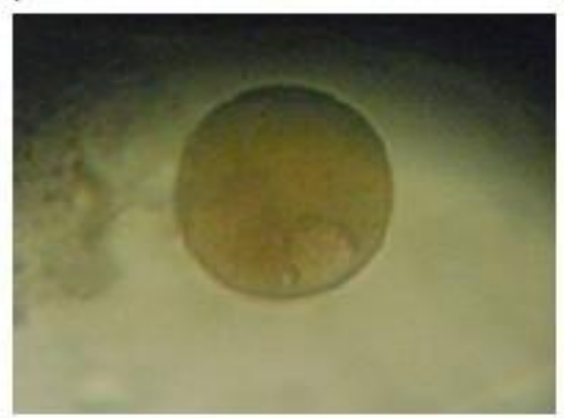

Plate 5. Cyst of Balantidium coli $(720 \mathrm{X})$

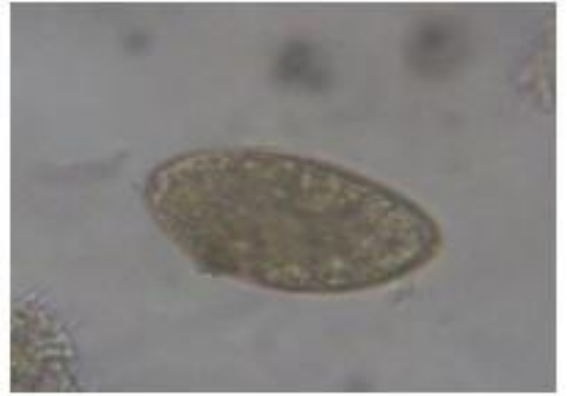

Plate 2. Egg of Fasciola sp. (720X)

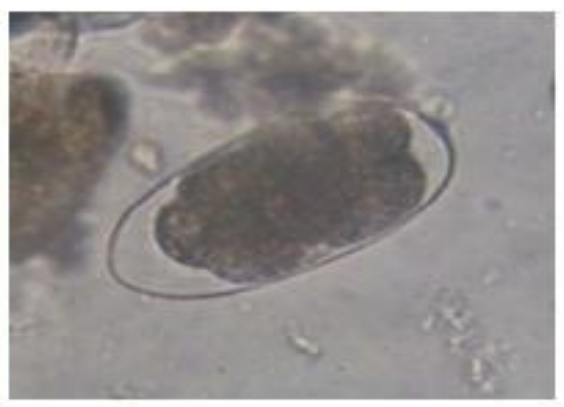

Plate 4. Egg of Stomach worm $(720 \mathrm{X})$

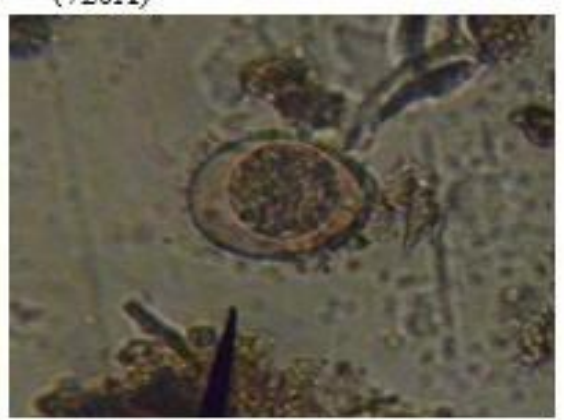

Plate 6. Oocyst of Eimeria sp. (720X)

Moreover, in this study, year was divided into two seasons but in other parts of the world there were four seasons. So, this difference in the division of seasons had made some over lapping of months and seasons.

In summer, prevalence were relatively higher in case of Paramphistomum sp. $(22.06 \%)$ followed by that of hook worm (20.59\%), stomach worm (17.65\%), Eimeria sp. (7.35\%), Fasciola sp. (7.35\%), Oesophagostomum sp. (2.94\%) and B. coli $(1.47 \%)$. In winter, prevalence was somewhat higher in case of hookworm $(20 \%)$ followed by Paramphistomum sp. (18.33\%), stomach worm (18.33\%), Fasciola sp. (10\%), Eimeria sp. (5\%), Strongyloides sp. (1.67\%) and B. coli (1.67\%).

In conclusion, it can be said that gastrointestinal parasites are highly prevalent $(69.29 \%)$ in the deer at Char Kukri Mukri, Bhola. The present study has shown both prevalence and load of gastrointestinal parasites of deer at Char Kukri Mukri. Our study provides a first overview on parasites in deer in the vicinity of villages, but to evaluate parasite transmission dynamics, much more studies are required on livestock in the area and on wild 


\section{B. C. Barmon and others}

herbivores. So, further study may also be conducted to keep restores the ecological balance as well as to assess the losses on economic point of view, due to parasitic diseases of deer.

\section{REFERENCES}

1. Banerjee PS, Rajat G, Yadav CL and Hira R (2005). Parasite infection in some wild animals of Uttaranchal. Indian Journal of Animal Science 75: 206-208.

2. Chapman D and Chapman N (1997). Fallow deer: their history, distribution and biology: Machynllenth Coch-ybonddu Books, 139-156.

3. Chroust K and Chroustova E (2004). Giant liver fluke (Fascioloides magna) in cervids in South Czech regions. Veterinarstvi 54: 296-304.

4. Cisek A, Balicka-Ramisz A, Ramisz A and Pilarczyk B (2004). Monitoring of parasitic fauna in wild animals in the Western Pomerania Region. Folia Universites Agriculturae Stetinensis, Zootechnica 46: 15-20.

5. Cook TW, Ridgeway BT, Androeid R and Hodge J (1979). Gastrointestinal helminths in white tailed deer of Iuinois. Journal of wildlife diseases 15: 405-407.

6. Fletcher TJ (1982). Management problems and disease in farmed deer. The Veterinary Record 111: 219-223.

7. Fox MT (2000). Pathophysiology of gastrointestinal nematode parasitism in ruminants-an update. Acta Parasitology 45: 253 .

8. Goossens E, Dorny P, Boomker J, Vercammen F and Vercruysse J (2005). A 12-month survey of the gastrointestinal helminths of antelopes, gazelles and giraffids kept at two zoos in Belgium. Veterinary Parasitology 127(34): 303-312.

9. Islam SKMA, Ahmed S, Hoque MA, Alim MA and Hassan MM (2003). Gastrointestinal parasites of captive deer and their response to selected anthelmintic. Bangladesh Veterinary Journal 37: 63-66.

10. Kanungo S, Das A, Das GM and Shakif-ul-Azam (2010). Prevalence of gastro-intestinal helminthiasis in captive deer of Bangladesh. Wayamba Journal of Animal Science 2: 42- 45.

11. Lim YAL, Ngui R, Shukri J, Rohela M and Mat NHR (2008). Intestinal parasites in various animals at a zoo in Malaysia. Veterinary Parasitology 157: 154-159.

12. Mackintosh CG and Wilson PR (2003). Impact of diseases on the NZ deer industry. In 63rd Conference of the New Zealand Society of Animal Production, Queenstown, New Zealand, 25-27 June, 2003. Proceeding of the New Zealand Society of Animal Production 63: 262-268.

13. Maia MJ (2001). The helminth fauna of the red deer (Cervus elaphus) and fallow deer (Dama dama) in Tapada Nacional de Mafra. Revista Portuguesa de Ciencias Veterinarias 96: 81-84.

14. Mason P (1994). Parasites of deer in New Zealand. New Zealand Journal of Zoology 21: 39-47.

15. Mason PC and Gladden NR (1983). Survey of internal parasitism and anthelmintic use in farmed deer. New Zealand Veterinary Journal 31: 217-220.

16. Mckenzie ME and Davidson WR (1989). Helminth parasites of intermingling axis deer, wild swine and domestic cattle from the island of Molokai, Hawadii. Journal of wildlife diseases 25: 252- 257.

17. Mutani A, Kamara R and Gabriel B (2003). A preliminary investigation on the gastrointestinal helminths of the Barbados green monkey, Cercopithecus aethiops sabaeus. Revista do Institute de Medicina tropical SaoPaulo 45: 193-195.

18. Novobilsky A, Horackova E, Hirtova L, Modry D and Koudela B (2007). The giant liver fluke Fascioloides magna (Bassi 1875) in cervids in the Czech Republic and potential of its spreading to Germany. Parasitology Research 100: 549-553.

19. Pacon J (1994). Parasites of mouflons, stags and roe-deer from the Lower Silesia region. Wild Parasitology 40: 279-92.

20. Parasani HR, Momin RR, Maradin MG and Veer S (2001). A survey of gastrointestinal parasites of captive animals at Rajkot munipical corporation zoo, Rajkot, Gujarat. Zoo's print journal 16: 604-606.

21. Pilarczyk B, Balicka-Ramisz A, Ramisz A and Lachowska S (2005). The occurrence of intestinal parasites of roe deer and red deer in the Western Pomerania voivodeship. Wiadomosci Parazytologiezne 51: 307-310.

22. Rehbein S, Walburga L and Visser M (2001). Winter Beitrage zur Kenntnis der parasitenfauna des Wildes in Nordrhein-Westfalen. Deer Endoparasitenbefall des Damwildes. Z Jagdwiss 47: 1-16.

23. Santin DM, Alunda JM, Hoberg EP and Fuente CDL (2004). Abomasal parasites in wild sympatric cervids, red deer, Cervus elaphus and fallow deer, Dama dama, from three localities across Central and Western Spain: relationship to host density and park management. Journal of Parasitology 90: 1378-1386. 
24. Shibashi T, Shimamura A, Izumo A and Nogami S (2003). A survey of parasites in the feces of Sika deer, Cervus nippon, from Kanagawa, Saitama and Chiba prefectures, Japan. Japanese Journal of Zoo and Wildlife Medicine 8: 95-99.

25. Singh PLD, Gupta MP, Sharma S and Sharma DR (2009). Epidemiology and chemotherapy of parasitic infections in wild omnivores in the Mechendra Choudhury Zoological park, Chhat Bir, Punjab. Journal of Threatened Texa 1: 62-64.

26. Soulsby EJL (1982). Helminlths, Arthropods and Protozoa of Domesticated Animals. $6^{\text {th }}$ ELBS, Bailliere, Tindall, London 785-791.

27. Vengust G (2003). Comparison of the parasitic fauna of fallow deer (Dama dama) from two enclosures in Slovenia. Slovenia Veterinary Research 40: 27-31. 